Tesis. Año 13, 12(15), 2019, 117-140

\title{
Plataiormas modernizadoras en el periodo de José Luis Bustamante y Rivero (1945-1948): revistas y proyectos intelectuales en una Lima demecrática
}

\author{
Zandor Emerson Zarria Ibarra \\ zzarria@gmail.com
}

\section{Resumen}

La investigación busca reseñar algunas de las más importantes plataformas modernizadoras que, mediante sus propios mecanismos de producción cultural, buscaron renovar el imaginario cívico, literario y artístico de la ciudad de Lima, correspondientes al periodo democrático de José Luis Bustamante y Rivero (1945-1948). En primer lugar, desarrollamos algunas ideas sobre el contexto cultural de Lima en la época mencionada, además de ubicar las coordenadas ideológicas en que se ubican algunos intelectuales relevantes. En segundo lugar, planteamos una definición del concepto 'plataforma modernizadora'. Finalmente, nos proponemos explicar los objetivos y el desarrollo de las siguientes plataformas modernizadoras o proyectos intelectuales de la época: la revista Las Moradas (1947-1949), la agrupación Espacio, la Peña Pancho Fierro (1936-1967), y las revistas El Correo de Ultramar (1947) y Mar del Sur (1948-1953).

Palabras clave: plataforma modernizadora, proyecto intelectual, lo moderno, producción cultural, revista.

\section{Abstract}

The research seeks to review some of the most important modernizing platforms that, through their own mechanisms of cultural production, sought to renew the civic, literary and artistic imaginary of the city of Lima, corresponding to the democratic period of José Luis Bustamante y Rivero (1945-1948 ). In the first place, we developed some ideas about the cultural historical context of Lima at the time mentioned, in addition to locating the ideological coordinates in which some relevant intellectuals are located. Secondly, we propose a definition of the concept 'modernizing platform'. Finally, we propose to explain the objectives and development of the following modernizing platforms or intellectual projects of the time: Las Moradas magazine (1947-1949), the Espacio group, la Peña Pancho Fierro (1936-1967), and the magazines El Correo de Ultramar (1947) and Mar del Sur (1948-1953).

Key words: modernizing platform, intellectual project, the modern, cultural production, magazine. 


\section{Plataformas modernizadoras en el periodo de José Luis Bustamante y Rivero (1945-1948): revistas y proyectos intelectuales en una Lima demecrática}

\section{Introducción: la primavera democrática de 1945}

Hacia la segunda mitad de los años cuarenta, Lima verá el incremento paulatino de un grupo de artistas y escritores que, relacionados a la poesía, la pintura, la filosofía o la ciencia histórica, desarrollarán sus prácticas de producción cultural a partir de un interés universalista. Nos encontramos, por supuesto, ante un singular grupo de intelectuales relevantes en sus respectivos saberes, además de que conciben la cultura en términos amplios: un concepto de cultura cuyos cimientos descansan en una idea de universalidad y espíritu democrático. Luis Rebaza Soraluz (2017) sostiene que estos escritores y artistas se adscriben a opciones políticas que "consistieron en tomar distancia de posiciones populistas y en afirmar, a su vez, el establecimiento de un sistema democrático, entendido este en el sentido más amplio" (p. 17). El ambiente político de democracia que se empezaba a vivir después de muchos años, aunado al ánimo universal democrático luego de la victoria de los Aliados en mayo de 1945, gestó aún más el espíritu de libertad y la aparición de escritores que, independientemente de sus apuestas culturales, ejercían una voz de cambio que estuviera direccionada por principios ético-democráticos y no por intereses partidarios o políticos. Jorge Basadre (1981) recuerda:

Había surgido ya desde 1945 en la juventud una generación post-aprista. Al social republicanismo asociáronse varios entre los mejores exponentes de ese sector, incluyendo grandes figuras de la literatura y del arte posteriores. Dirigió La Nación, diario del movimiento hasta noviembre de 1946, Sebastián Salazar Bondy y en el período ulterior Alfredo Cánepa Sardón. Tuvimos la promesa de numerosos senadores y diputados en el sentido de que se incorporarían a nuestro grupo; pero maniobras oscuras hicieron fracasar este enfático anuncio. (p. 715)

Las "maniobras oscuras" a que se refiere Basadre revela la existencia de fuerzas políticas (no pocas) que, sin descanso, trabajaron entre 1945 y 1948 por 
desestabilizar el régimen democrático de José Luis Bustamante y Rivero. Este había llegado al poder para iniciar un gobierno excepcionalmente respetuoso de las leyes, la libertad y con una firme voluntad de lograr el desarrollo de la nación a partir de la igualdad de derechos. Para defender este régimen (firme en sus inicios y deleznable con el paso del tiempo), Basadre y otros intelectuales fundan el Partido Social Republicano, cuyo órgano de difusión fue el diario $L a$ Nación, donde trabajaba Sebastián Salazar Bondy. Él y otros intelectuales como Raúl Deustua, Blanca Varela, Jorge Eduardo Eielson, Javier Sologuren, Fernando de Syszlo y Ricardo Tenaud pueden enmarcarse en aquella generación de jóvenes con una consciencia política crítica y no partidaria, "post-aprista", como dice Basadre, puesto que sus intereses culturales (universales) dialogan con una participación cívica democrática y moral. Todos ellos aglutinan, según Guillermo Rochabrún (2009), una "óptica ético existencial con la que aspiraban a una modernidad universal, humanista y espiritual, antes que racionalista" (p. 370). Su participación será decisiva en algunos proyectos intelectuales de la época: el libro la Poesía contemporánea del Perú, la agrupación Espacio y la revistas Las Moradas y El Correo de Ultramar.

El periodo de gobierno de Bustamante y Rivero significó la apertura democrática plena y la búsqueda permanente de la igualdad de derechos. Julio Cotler (1987) anota que solo entre 1945 y 1947 fueron reconocidos 264 sindicatos en todo el Perú, cantidad que duplica las organizaciones sindicales legalizadas por Manuel Prado en el periodo anterior (pp. 265-266). Del mismo modo, aunque no existía un programa económico claro, el régimen de Bustamante se trazó el objetivo de elaborar políticas sociales que reconozcan los derechos laborales, y brinden acceso a la educación y a la salud pública, todo en aras de construir una mejor economía, pero también un país más integrado socialmente (Cueto y Contreras, 2013, p. 300) Por otro lado, el ambiente de libertad y apertura cultural fue particularmente evidente para la sociedad en su conjunto. Al respecto, Washington Delgado (2008) recuerda el entusiasmo cultural de estos años:

Entre 1945 y 1948, no sólo se abrieron cárceles y fronteras, también se abrieron las ventanas al aire de la cultura. De Europa, de los Estados Unidos, de los otros países latinoamericanos llegaron los libros, las revistas, las películas, las obras teatrales, el pensamiento. (p. 153)

Delgado (2008) recuerda que los jóvenes de aquellos años, congéneres suyos, se vieron muy influenciados por la obra existencialista de Sartre, Heidegger y Camus, así como por las películas europeas que, desde 1945, llegaron de Suecia, Rusia, Inglaterra y Francia, sin olvidar el cine neorrealista italiano de Rosellini, De Sica, Lattuada, De Sanctis y Visconti (p. 153). Incluso ya en 1943 (como lo reseña la revista de arte plástico Nuestro Tiempo un año después, es decir, en 1944) se proyectan en Lima películas como Casablanca de Michael Curtis, Crimen y Castigo de Pierre Chenal, Jornada de terror de Orson Wells y 
La sombra de una duda de Alfred Hitchcock, la mayoría de ellas adaptaciones de novelas. Las "cárceles", "fronteras" y "ventanas culturales" que, en palabras de Washington Delgado, se abrieron en 1945 constituyen la consolidación del clima de efervescencia cultural que, iniciado sordamente hacia fines de los años treinta ${ }^{1}$, tiene ahora un momento de reflujo gracias al régimen democrático recientemente instalado.

\section{Plataformas modernizadoras}

En estos años, empiezan a surgir algunas "plataformas modernizadoras", como las ha denominado Luis Rebaza Soraluz². Entre ellas, destacan la Alianza de Intelectuales Antifascistas, el Frente Democrático Nacional, el Partido Social Republicano, el diario La Nación, La Editorial Cultura Antártica, la agrupación Espacio, la Galería de Lima, la Peña Pancho Fierro, y las revistas Mar del Sur, Las Moradas y El Arquitecto Peruano. (Rebaza, 2017, p. 80). A esta lista, nos gustaría añadir las revistas Historia, Nuestro Tiempo y Correo de Ultramar. Aunque en su libro De Ultramodernidades y sus contemporáneos ${ }^{3}$ Rebaza Soraluz no propone una definición de lo que es una plataforma modernizadora, es algo que se puede colegir (no sin cierta complejidad) a partir del contenido de su investigación. En nuestro caso, por supuesto, sí quisiéramos proponer una definición de este concepto: de acuerdo con el contexto que vivía Lima en la segunda mitad de los años cuarenta, una plataforma modernizadora puede entenderse como el espacio físico, escrito, visual o simplemente discursivo que, apoyado por medios propios de la dinámica de la vida cultural y cívica de una ciudad (como las salas de exposiciones, la prensa escrita, la actividad editorial o las reuniones políticas), busca modernizar el imaginario cultural de sus habitantes, ya sea (1) defendiendo los ideales de libertad y democracia (y por tanto la conceptualización de un arte libre); (2) promoviendo una apertura a valores culturales contemporáneos provenientes del extranjero; (3) impulsando el reconocimiento de otras tradiciones culturales peruanas (el saber precolombino); o (4) combatiendo las ideologías autoritarias de las clases dominantes, el indigenismo ortodoxo en la pintura, el hispanismo exacerbado o las corrientes que reivindicaban una literatura bajo el yugo político.

Una vez que hemos propuesto una definición de lo que supone una plataforma modernizadora en el contexto de estos años, quisiéramos, ahora sí, plantear cuál fue el desarrollo de estas plataformas en el proceso cultural de la ciudad y qué relaciones podemos encontrar entre ellas, comprendiendo que, en varios casos, se trató de una red de artistas, escritores e ideas que intentaban modernizar el aún incipiente imaginario cultural de Lima. Nos interesa, sobre todo, reseñar aquellas plataformas modernizadoras vinculadas estrictamente al terreno cultural y que se desarrollaron durante el breve periodo democrático de José Luis Bustamante y Rivero (1945-1948), pues fue precisamente esa fase 
de la vida política del país la que promovió la creación de estos proyectos intelectuales. Por esa razón, no podremos dedicar un espacio a las revistas Historia y Nuestro Tiempo (cuyo comentario justificaría un estudio aparte). En las siguientes páginas, nos abocaremos a examinar el rol que, en estos años, cumplieron la revista Las Moradas, la agrupación Espacio, la Peña Pancho Fierro, y las revistas El Correo de Ultramar y Mar del Sur.

\subsection{Las Moradas: el proyecto moderno y cosmopolita de Emilio Adolfo Westphalen}

En el primer semestre de 1947, Emilio Adolfo Westphalen inició la publicación de Las Moradas (1947-1949). Con un tiraje de solo 1000 ejemplares y distribuida en librerías y quioscos, la revista, en sus dos años de existencia, pudo situarse como un proyecto intelectual moderno y cosmopolita que buscó renovar el imaginario peruano. Las Moradas. Revista de las Artes y las Letras abarcó todos los campos vinculados a la cultura: la literatura, el arte, la historia, la arquitectura, la psicología, la filosofía y, en un menor grado, la música. La reflexión crítica será el bastión de esta revista que enarbolará un modo nuevo de entender el arte y el proceso de creación artística. Esto significa dejar de lado condicionamientos locales o particulares como el indigenismo o el hispanismo anticuado; reivindicar toda obra por su renovadora expresión formal; sublimar la experiencia espiritual del individuo como componente fundamental en la creación, y rescatar la tradición precolombina en tanto saber primigenio del hombre y depósito del inconsciente colectivo como alternativa a la racionalidad propia de la modernidad. En ese sentido, la revista dirigida por Westphalen prestará especial atención a las corrientes artísticas y literarias en boga en la Europa de Posguerra, como el surrealismo, el abstraccionismo en la pintura, la arquitectura moderna y el interés por las tradiciones culturales no occidentales. Al respecto, Rebaza Soraluz (2017) ha señalado que, con Las Moradas, Westphalen "recupera el proyecto de modernizar el modernismo y hacer contemporáneo el arte en el Perú sirviéndose de instrumentos conceptuales de fuente científica que articulen la multiplicidad cultural y el legado andino"5 (p. 73). La revista estará siempre abierta a la comprensión del arte precolombino y las expresiones culturales de los pueblos primigenios americanos. Un hecho que no podemos olvidar sobre Las Moradas es que, además de su singular director ${ }^{6}$, esta revista nuclea a un importante grupo de jóvenes peruanos que, en su mayoría, serán fundamentales para la cultura de esos años y las décadas posteriores: Jorge Eduardo Eielson, Sebastián Salazar Bondy, Fernando de Szyszlo, Javier Sologuren, Blanca Varela, Ricardo Tenaud, José Durand, entre otros.

Las Moradas proyecta, a lo largo de sus cientos de páginas, la creación de un artista cuya obra esté signada por las esencias y las preocupaciones del espíritu, más que por los condicionamientos cotidianos o contemporáneos: no es el re- 
flejo de la realidad lo que inquieta al creador, sino su expresión interior a partir de las circunstancias externas que lo rodean. Con una visión indiscutiblemente moderna, Westphalen presenta, al final del primer número, un pequeño texto que bien puede leerse como un manifiesto de la revista: el cambio, la reflexión y la búsqueda constantes son los pilares de esta nueva empresa:

Cuando salimos a la aventura, a la caza de las presas espirituales, pensamos siempre que habremos de volver a unas MORADAS, donde habrá amparo para lo atesorado, que no habremos de llevar siempre a cuestas. Punto de reunión, para el contacto, para el cambio, para la confrontación de hallazgos, pero lugar donde toda conquista del espíritu, donde todo descubrimiento del arte y de la poesía, de la ciencia y del pensamiento, no habrá de considerarse nunca como un punto final, como un acabamiento, sino como un acicate hacia nuevas conquistas, como un despliegue de posibilidades futuras. (Las Moradas, 1947, p. 107)

La discusión, como vemos, jamás estará concluida: será determinada por el cambio constante de afirmación y negación. La reflexión, la crítica y el pensamiento del artista, del intelectual, se verán en esa frecuente duda y pregunta de lo no acabado, pues es el único modo de avanzar hacia el futuro. Recordemos que Octavio Paz (1974), refiriéndose al arte moderno, sostiene una idea similar: "El arte moderno es moderno porque es crítico. Su crítica se desplegó en dos direcciones contradictorias: fue una negación del tiempo lineal de la modernidad y fue una negación de sí mismo.” (p. 194) Es en ese sentido que Las Moradas constituye una muestra singular del modernismo o expresión cultural moderna dentro del contexto de la modernidad': una revista que apuesta por el cambio, por la duda, por la libertad de la obra y el flujo cambiante de la mente del artista.

Quisiéramos mencionar también el alto grado de cosmopolitismo que tuvo la revista: su principal anhelo fue modernizar el arte y la literatura en el Perú a partir del contacto continuo con las nuevas ideas provenientes de Europa, Estados Unidos y México. En Las Moradas, son traducidos, discutidos o reproducidos textos de y sobre Marcel Proust, Soren Kierkegaard, Wolfgang Paalen, T.S. Eliot, Ezra Pound, Alfonso Reyes, Juan Larrea, Leonora Carrington, Pierre Reverdy, Karl Jaspers, entre otros. La traducción, en cierto modo, se profesionaliza y se busca lograr, en el Perú, una comunidad lectora que pueda tener acceso a ideas que el ambiente cultural peruano de la época apenas conoce: el arte abstracto, las expresiones plásticas no figurativas, la arquitectura moderna, la poesía surrealista, las novelas de Kafka y Proust, así como los avances etnográficos que estudian a las culturas precolombinas. Ina Salazar (2011) ha valorado el aporte inmenso de Las Moradas y Amaru: ambas "inyectaron una energía nueva, estimularon el medio, ampliaron los campos de interés e instauraron una actitud al mismo tiempo exigente, rigurosa y de apertura" que significaba 
el importante rol de una revista capaz de "franquear las fronteras localistas y conservadoras" (p. 15). Nos encontramos ante una revista que, similar al caso de Amauta, logra establecer una red de comunicación intelectual que permite al Perú estar comunicado con Europa, Estados Unidos y, principalmente, México. Gracias a la presencia de César Moro en este país, Las Moradas deviene un foco de atracción al que llegarán las ideas y textos provenientes de autores mexicanos como, por ejemplo, Alfonso Reyes y Agustín Lazo. Finalmente, destacamos, la frecuente promoción de revistas extranjeras cuyos anuncios aparecen al final de cada número de Las Moradas. ${ }^{8}$ Algunas de ellas son Letras de México (México); Realidad. Revista de Ideas (Argentina); América. Cabiers France-Amerique Latine (Francia); El Correo de Ultramar (Lima); The Tiger's Eye (Nueva York); Orígenes. Revista de Arte y Literatura (Cuba); Ciclo. Revista Bimestral. Arte, literatura pensamiento modernos. (Argentina); Partisan Review (New York), y Prometeus. Revista mexicana de Literatura (México).

\subsection{La Agrupación Espacio}

En mayo de 1947, no solo aparece Las Moradas en circulación, también se inician las actividades de otra plataforma modernizadora cuyo rol en el arte y la arquitectura es muy importante ponderar: la Agrupación Espacio9. Se trata de un conjunto de artistas plásticos y escritores, pero fundamentalmente arquitectos y estudiantes de la antigua Escuela Nacional de Ingenieros (hoy Universidad Nacional de Ingeniería), todos ellos liderados por el arquitecto y periodista Luis Miró Quesada Garland. El grupo tenía como objetivo impulsar una arquitectura y arte modernos en el país, buscando el encuentro del hombre nuevo, el hombre contemporáneo, con su espacio y momento universal: "Entre el mundo de ayer y el mundo de hoy, se ha establecido el origen de la experiencia más honda de la historia; la génesis de un hombre nuevo y la elaboración de su mensaje." (Agrupación Espacio, 1947, párr. 3). E1 “mundo de hoy" es el terreno propicio para la ejecución del arte moderno, el cual busca enlazar a la humanidad con su experiencia más profunda y verdadera. Al respecto, José Ignacio López Soria (1997) anota que los miembros de Espacio "afirman la novedad del mundo contemporáneo que consiste, para ellos, en cambios fundamentales que están ocurriendo en los dominios del ser, del conocer y del hacer, y que conducen al descubrimiento del hombre como el valor primordial" (párr. 14).

El fenómeno de Espacio no solo debe circunscribirse, como suele afirmarse, al terreno del arte y la arquitectura. Los miembros del grupo y los allegados a él formaban parte de un ambiente modernizador en la ciudad de $\operatorname{Lima}^{10}$ que los impulsaba a escribir en diarios y revistas ${ }^{11}$, organizar conferencias y veladas musicales, ejercer la crítica de arte y literatura, discutir proyectos urbanísticos, escribir memoriales sobre temas culturales a las autoridades políticas, asistir a 
reuniones de la Municipalidad de Lima, entre otras actividades (López Soria, 1997, párr. 25).

Por otro lado, debemos ponderar que los principios de Espacio deben su creación al libro Espacio en el tiempo: la arquitectura moderna como fenómeno cultural (1945) de Luis Miró Quesada Garland, así como a las propuestas modernas de Le Corbusier (base conceptual también de Miró Quesada) y el "no-estilo", ya vigentes en Europa en años anteriores. La declaración de principios de Espacio publicada en El Comercio el 15 de mayo de 1947 nos ofrece una orientación de su propuesta estética y cultural:

$\mathrm{E} 1$ arte, como medio de manifestación integral y vivencia más propia de la naturaleza humana, resume e integran casi su totalidad la comunicación del ser contemporáneo y se realiza para definirlo. En él se desarrolló todo un proceso espiritual y material, ya no como la historia objetiva y narrativa de un simple transcurrir de normas, sino como la realización cuidadosamente elaborada de estos procesos, por la actitud del hombre frente a ellos. El arte no expresa una forma en sí o por sí, sino el total de una experiencia humana ante los esenciales valores que integran el campo dinámico del ser. (párr. 4)

Esta concepción del arte como parte de un proceso espiritual que responde al "total de la experiencia humana" es una consigna moderna defendida por los intelectuales y artistas que luchan por encauzar los senderos de la cultura y la democracia en la Lima de aquellos años. Además de los arquitectos ${ }^{12}$ que firman la declaración de principios de Espacio, hay una lista de adherentes, en la que pueden leerse los nombres siguientes: Samuel Pérez Barreto, César de la Jara, Xavier Abril, Jorge Eduardo Eielson, Javier Sologuren, Sebastián Salazar Bondy, Fernando de Szyszlo, Jorge Piqueras, Raúl Deustua, Carlos Alejandro Espinoza, Emilio Herman S., Leopoldo Chariarse, Miguel Grau Schmidt, Joao Luiz Pereira y Luis León Herrera. Esto confirma, por supuesto, que la Agrupación Espacio estuvo ligada, desde su fundación, a un conjunto de poetas, artistas e intelectuales que serán decisivos en la creación y preparación de las plataformas modernizadoras que ahora nos atañe ${ }^{13}$. Varios de estos escritores estuvieron relacionados a los medios de comunicación escrita, lo que coadyuvó al flujo y mayor difusión de sus ideas. Fernando de Szyszlo (2016) recuerda:

Una parte importante de lo que sucedió con todo ese movimiento que surgía entre los artistas e intelectuales peruanos más vanguardistas fue la difusión que le dimos a todas esas ideas. De alguna manera nos apoderamos, o propiciamos, las posiciones estratégicas de la comunicación cultural. Porque no solamente íbamos obteniendo la información y los conocimientos, sino que queríamos compartirlos para mejorar el nivel, sin duda. En eso tuvimos muchas ayudas. Los diarios El Comercio y La 
Prensa nos dieron mucho espacio. La sección cultural de La Prensa era dirigida por Pepe Durand Flórez. (p. 81)

José Durand Florez, joven investigador en historia y literatura, también participó en Las Moradas, en la que escribieron De Szyszlo, Sologuren, Varela, Eielson y Salazar Bondy, siendo estos dos últimos colaboradores asiduos de $L a$ Prensa y La Nación. Lo mismo podemos decir de la participación de todos ellos en revistas como Mar del Sur (1948-1953) y El Correo de Ultramar (1947). Asimismo, gran parte de las ideas de Espacio fueron difundidas gracias al diario $E l$ Comercio, en ese momento dirigido por Luis Miró Quesada de la Guerra, padre de Luis Cartucho Miró Quesada, impulsor y líder de la mencionada agrupación. Espacio pudo canalizar, así, sus manifiestos y comunicaciones a través de artículos semanales en El Comercio entre 1947 y 1950, tras lo cual el grupo funda una revista propia, denominada Espacio, que funcionaría como órgano de comunicación oficial.

\subsection{El Correo de Ultramar: una revista singular en 1947}

El Correo de Ultramar. Quincenario de Letras, Artes e Información es acaso una de las publicaciones más singulares de la época. Estuvo dirigida por Jorge E. Eielson y Jean Supervielle, agregado cultural de Francia e hijo del poeta franco-uruguayo Jules Supervielle ${ }^{14}$. La revista se presenta como quincenario y, a diferencia de otras publicaciones culturales de la época, su formato es grande, tipo tabloide, de mayores dimensiones que las del diario El Comercio. El Correo de Ultramar constituye un importante enlace con la cultura europea y francesa del momento; la revista nace con dos propósitos claros: informar sobre "los acontecimientos humanos allende los mares" y conectar al público limeño con "la vida espiritual que se desarrolla, no solo en Francia y en el Perú, sino en todo el mundo, conforme lo requiere un sentido más profundo y unitario de la cultura" (El Correo de Ultramar, 1947a, p. 1).

En sus cuatro únicos números (aparecidos en los últimos meses de 1947), El Correo de Ultramar recorre los caminos actuales de la literatura y el arte principalmente europeos: textos sobre Picasso, el surrealismo, la pintura francesa actual, el existencialismo, Gérard de Nerval, Rodin, Sartre, Proust, Kafka, y la poesía de Pedro Salinas son solo algunos de los tópicos desarrollados. También, por supuesto, se presta atención a autores nacionales, aunque en menor grado que los referentes europeos: Eielson, Salazar Bondy y Vallejo. Sobre la vida y obra de Vallejo, destacamos el ensayo de Westphalen "Un poema de Vallejo vertido al francés" y una curiosa convocatoria lanzada por Ernesto More, director del espacio radial Ecos de Francia, en la que se solicita al público el envío de testimonios y recuerdos de aquellos que hubieron de conocer a César Vallejo a fin de leer sus trabajos en una audición pública. Esto constituye una característica importante de la revista: además de la difusión sobre la actualidad cultural 
del exterior (principalmente europea y francesa ${ }^{15}$ ), se propone ser un espacio de integración y producción de valores culturales en Lima, ya sea con actos públicos como este o la convocatoria lanzada desde el segundo número llamada "Encuesta sobre existencialismo", cuyo contenido supone básicamente preguntas para acercar al público a esta corriente filosófica proveniente de Europa. El valor más perseguido por los editores de la revista es conectar al público lector con estas corrientes y tendencias actuales, consideradas como hitos fundamentales de la cultura universal, así como encontrar los medios de universalizar nuestro propio legado:

El momento decisivo ha sido aprovechado por un grupo de jóvenes del Perú, los que ahora presentan "El Correo de Ultramar", quienes ofrecen sus páginas con el exclusivo fin de alcanzar un mayor contacto de la cultura universal con la nuestra, y lo que es más imperioso aún, con el fin de trabajar por una vigencia más universal de nuestra cultura. (El Correo de Ultramar, 1947a, p. 1)

Aunque en los tres primeros números figuran como redactores Raúl Deustua, Sebastián Salazar Bondy, Javier Sologuren y Ricardo Tenaud, este grupo se amplía en el último número con la presencia de José María Arguedas, Jorge Bresciani, Enrique Iturriaga y Fernando de Szyszlo ${ }^{16}$. Así vemos uno de los varios puntos de diálogo que esta revista mantiene con Las Moradas: la mayoría de estos escritores y artistas (varios de ellos de generaciones distintas) participan en ambas revistas; la presencia de Westphalen es evidente; los valores culturales y estéticos, así como los artistas reseñados, son en varios casos los mismos ${ }^{17}$; la pléyade de escritores y redactores está vinculada, como hemos visto ya, a las dos revistas y también a la Agrupación Espacio. Finalmente, nos interesa anotar que El Correo de Ultramar impulsa a otra plataforma de modernización cultural de indiscutible relevancia en esos años:

El mismo día que quedaba cerrada esta edición, abrió sus puertas la nueva galería de arte del señor Francisco Moncloa, con la denominación indicada. El noble esfuerzo ha sido recibido en la forma más cordial y con un éxito sobresaliente en el ámbito cultural y artístico de esta ciudad, que, hasta la fecha, carecía de una sala de exhibición permanente, al estilo de las grandes metrópolis. (El Correo de Ultramar, 1947b, p. 3)

La institución mencionada es la Galería de Lima, fundada en 1947 y considerada como la primera galería de arte en la ciudad, ya que antes las exposiciones se realizaban en academias de música o institutos cuyos espacios no estaban inicialmente preparados para esta tarea ${ }^{18}$. Así, se intentó cubrir "este vacío indudable de que adolece nuestra ciudad - peligroso para el desarrollo de nuestro arte pictórico-, [que] viene a llenarlo una nueva empresa que se propone instalar una galería de tipo moderno" (E1 Correo de Ultramar, 1947c, p. 
3). 1947 resulta así un año significativo debido a la aparición de las plataformas modernizadoras arriba reseñadas, considerando que, un año antes, en 1946, la editorial Cultura Antártica, dirigida por Raúl Porras Barrenechea, había ya gestado la aparición de dos libros importantes que discutirían la necesaria renovación de los conceptos y los motivos de la creación poética y pictórica: $L a$ poesía contemporánea del Perú y La pintura contemporánea en el Perú. El primero, preparado y editado por Sebastián Salazar Bondy, Jorge Eduardo Eielson y Javier Sologuren, reclama y reivindica una poesía escrita a partir de criterios puramente poéticos y donde no existan condicionamientos sociales, raciales o determinantes culturales específicas ${ }^{19}$. El segundo libro fue escrito por Juan Ríos, autor teatral y crítico de arte, director de la revista Nuestro Tiempo, en cuyas páginas apuesta por una pintura independiente. Es en esa revista donde Ríos publica los primeros fragmentos de su futuro volumen La pintura contemporánea en el Perú.

\subsection{La Peña Pancho Fierro: la presencia del Perú otro}

La modernización cultural en los años cuarenta no estuvo limitada solamente al encuentro del Perú con valores culturales foráneos, sino también a la búsqueda constante del saber proveniente de ese otro Perú tantas veces ocultado y a veces vilipendiado. En las décadas anteriores, el indigenismo había cumplido un papel importante en la valorización de la cultura andina, así como en la búsqueda de la modernización del país en tanto se esperaba la reivindicación social del indio. En ese sentido, la escuela indigenista en la pintura, la prédica política de Mariátegui y la obra de intelectuales como Luis E. Valcárcel y José Uriel García supuso el ingreso del tema andino en el espectro cultural del Perú. Sin embargo, es cierto que, todavía en los años 40, existían prácticas culturales propias de las élites letradas y la cultura oficial que no reconocían el alto contenido simbólico y la riqueza artística que guardaban las manifestaciones de las culturas aborígenes. Kelly Carpio y María Eugenia Yllia (2006) afirman que, en los años 40, es muy frecuente la "dificultad metodológica para describir el arte popular", llegando a ser normal una situación como la descrita:

En 1940, la prensa da razón de una exposición — probablemente la primera - de toros, platos y figurillas ecuestres de cerámica de $\mathrm{Pu}-$ cará presentada en la Peña Pancho Fierro. Según relataba el cronista, la muestra "reboza la espontaneidad de un arte sencillo, infantil si se quiere". Este tipo de argumentos teñidos de prejuicios decimonónicos de la antropología evolucionista, no eran exclusivos arte popular, pues en 1954, personalidades "entendidas" en arte como el arquitecto Luis Miró Quesada los seguirán arrastrando al describir las telas pintadas prehispánicas de la Cultura Chancay exhibidas en el Instituto de Arte Contemporáneo, IAC. 
Incluso los mismos indigenistas padecían de este tipo de estorbos conceptuales, pues la carga estética del arte popular era difícil de precisar sin establecer categorías de valoración. (Carpio e Yllia, 2006, pp. 48-49)

En efecto, la "carga estética" del arte popular y las manifestaciones culturales de las civilizaciones precolombinas no era aún un tema ampliamente comprendido. En ese sentido, una institución que batalló para lograr revalorar el arte popular fue la Peña Pancho Fierro, fundada en 1937 por las hermanas Alicia y Celia Bustamante (esposa de José María Arguedas durante varios años). La Peña, ubicada en el centro de Lima, constituyó un lugar fundamental desde el cual el saber de la cultura andina irradió a distintos artistas, intelectuales y escritores limeños e incluso extranjeros ${ }^{20}$. El lugar funcionó como sala de exposiciones artísticas, punto de encuentro y sobre todo salón de discusión intelectual. Además, gracias a la apertura mental de las hermanas Bustamante, la Peña Pancho Fierro (1937-1966) fue un centro cultural que albergó incluso a artistas y escritores que, en algún momento, habían discrepado de la pintura indigenista, como es el caso de César Moro (Carpio e Yllia, 2006, p. 48). Fernando de Szyszlo (2016) sostiene también que, a pesar de la firme convicción izquierdista de las hermanas Bustamante, muchas personalidades del mundo del arte y la cultura eran admitidas en la Peña (p. 43). Al respecto, Carpio e Yllia (2006) anotan:

El testimonio recogido por José Ricardo Respaldiza describe bien lo que allí sucedía: "Sabogal sentado en una de las bancas — durísimasfrente a César Moro y Emilio Westphalen. E1 indigenismo y el surrealismo bebiendo del filtro mágico de la Peña: un delicioso pisco de frutas, receta secreta de Alicia o Celia”. (p. 48)

Westphalen era muy amigo de José María Arguedas y las hermanas Bustamante, lo que explica su presencia en la Peña desde los años iniciales. Sabemos que a la Peña Pancho Fierro asistieron varios pintores e intelectuales y también, por supuesto, varios redactores y colaboradores de Las Moradas y El Correo de Ultramar, entre ellos Arguedas, Sologuren, Federico Schwab, César Moro, Ricardo Tenaud, De Syszlo, Blanca Varela, Eielson y Cueto Fernandini, así como intelectuales provenientes del extranjero: León Felipe, Pablo Neruda, Pedro Salinas, Rafael Alberti, Corpus Barga y Margarita Xirgu ${ }^{21}$. La Peña constituyó un faro cultural que no solo se limitó al intercambio intelectual y la revaloración de la cultura andina en Lima, sino que fue un factor decisivo en la poética de un grupo de jóvenes autores (De Szyszlo, Sologuren, Salazar Bondy, Eielson) que, en años posteriores, incorporó a su obra la vertiente cultural de las civilizaciones peruanas ancestrales: "En esa época ellos ponen énfasis en el estudio estético de una cultura europea que aprecia el arte americano precolombino y esto los diferencia de quienes los anteceden puesto que aquellos enfatizan el estudio social del mundo andino contemporáneo." (Rebaza Soraluz, 2000, p. 
119) Todos ellos, en conjunto con Arguedas y Westphalen, conformarán una suerte de comunidad intelectual que empieza a revalorar el arte precolombino en el contexto de una Lima que, como refiere Francisco Stastny (1981), empieza a consumir más objetos de arte andino, como textilería o artesanía (p. 88).

\subsection{8: Mar del Sur y la liquidación de los proyectos intelectuales modernos}

Como vemos, gran parte de estos intelectuales interactuaban en la Peña, así como escribían en importantes diarios limeños y revistas culturales de la época: El Comercio, La Crónica, La Prensa, Las Moradas, Correo de Ultramar o Mar del Sur. Precisamente, antes de finalizar nuestro trabajo, es necesario reseñar Mar del Sur (1948-1953). Esta revista cumple un rol destacado en estos años: sus páginas sirven como espacio de publicación para intelectuales ya mayores o de relativa madurez, como Alberto Tauro, José María Arguedas, Guillermo Lohmann Villena, Jorge Basadre, Raúl Porras, Luis Jaime Cisneros, Estuardo Núñez, Aurelio Miró Quesada, Enrique Peña Barrenechea, Manuel Moreyra Paz-Soldán, Francisco García Calderón, Martín Adán, E. A. Westphalen, Héctor Velarde y Paul Linder, al tiempo que es también palestra de nuevos valores literarios: André Coyné, S. Salazar Bondy, Blanca Varela, Leopoldo Chariarse, Raúl Deustua, Washington Delgado, Pablo Guevara, Luis Loayza y Abelardo Oquendo. De alguna forma, esta publicación, que aparece en octubre de 1948, supone un encuentro intergeneracional de intelectuales y escritores, por cuanto abarca dos momentos de la vida cívica de la ciudad: su trayecto vital se inicia en los meses finales del periodo democrático de Bustamante y termina en momentos convulsos durante la dictadura de Manuel Odría (19481956). Recordemos que, aunque Bustamante buscó modernizar el país a partir de una sociedad inclusiva, justa y con una idea de nación integrada, su política económica no fue la más acertada. El proceso inflacionario y el fracaso de la industrialización llevaron a la sociedad a una confrontación entre el Gobierno, el APRA y las clases dirigentes:

La crisis económica llevó a un enfrentamiento entre las clases sociales cada vez más agudo. Las clases medias empezaron a ver con simpatía los llamados de la élite a restablecer el orden y la autoridad a costa del APRA, para evitar una nueva guerra civil. Cuando la coyuntura económica empezó a deteriorarse, las élites económicas que defendían el liberalismo a ultranza y que habían estado paralizadas inicialmente, reaccionaron para oponerse a las inconsistencias del régimen, consiguiendo resquebrajar las bases sociales que sostenían al gobierno. (Cueto y Contreras, 2013, p. 302)

Esta situación terminó decantándose por un golpe de Estado (octubre de 1948) preparado por la derecha peruana, con lo que la oligarquía reestableció su 
hegemonía y dio la espalda a la democracia en el país. El nuevo régimen "añadió un tipo de control sobre los movimientos sociales, que combinaba la represión y el autoritarismo con el paternalismo clientelista y una persecución, muchas veces despiadada, a los políticos opositores al régimen" (Cueto y Contreras, 2013, p. 311). El silenciamiento de las voces críticas y la persecución fueron una constante del gobierno autoritario de Odría, y constituyó un periodo en que las plataformas modernizadoras en Lima sufrieron un duro embate: es cierto que algunas de ellas, vinculadas a la esfera estrictamente cultural, se mantuvieron aún a flote, pero debemos anotar que varios proyectos intelectuales de la época (revistas, conversatorios, reuniones políticas y cívicas) sucumbieron ante el nuevo orden autoritario que liquidó las libertades ganadas en 1945. Una excepción interesante de esto (acaso por el vínculo de su director con el diario El Comercio) fue Mar del sur, dirigida por Aurelio Miró Quesada Sosa y coordinada por Luis Jaime Cisneros Vizquerra. Como habíamos afirmado más arriba, Mar del sur aparece semanas antes del fin del gobierno de Bustamante y Rivero, por lo que aún existe

un ansia por conocer hechos e ideas, un urgente deseo de ver claro en los problemas y en los quehaceres de la época. Libros, revistas, conferencias, fuera de la meritísima labor de difusión de los periódicos, se han multiplicado en estos años como un signo grato y promisor, aunque no siempre con precisos perfiles. (Mar del Sur, 1948, p. 1)

La revista es consciente de esta nueva faceta de la cultura en el país (que pronto se verá lamentablemente truncada) y por ello propone una publicación de "completa y cabal amplitud", en la que puedan retratarse todos los temas que representen la "evolución espiritual del Perú". Sus objetivos son claros desde el primer número: (1) la exaltación de lo espiritual; (2) el concepto de la dignidad y la perfectibilidad de la persona humana; (3) el sentido cristiano y trascendente de la vida; (4) la necesidad de fijar las esencias nacionales, y (5) la convicción de un Perú íntegro en el espacio y en el tiempo. (Mar del Sur, 1948, p. 2) Aunque sus convicciones, al menos en términos formales, pueden integrarse a otros proyectos intelectuales de la época (la "exaltación de lo espiritual" y la búsqueda de un Perú "en el espacio y en el tiempo", como promulgaba Espacio), Mar del Sur se distancia de algunos proyectos modernizadores en tanto persigue principios como "el sentido cristiano y trascendente de la vida" y "la necesidad de fijar las esencias nacionales".

Mar del Sur abarca casi todas las áreas vinculadas a la cultura: poesía, filosofía, estética, relatos, ensayos históricos, arte plástico, filología y hasta estudios técnicos sobre problemas específicos en diversas zonas del país. Dentro de estos campos, sus intereses descansaron sobre todo en la historia y la cultura de los periodos colonial y republicano en el Perú, las crónicas de la conquista, las reflexiones sobre poesía y los ensayos dedicados a la filosofía y la cultura clásica 
europea $^{22}$. Un autor que es referente insoslayable para esta revista es Ricardo Palma, así como vemos también algunos números dedicados al Inca Garcilaso de la Vega, a José de San Martín y a la Universidad San Marcos. El interés histórico de la revista es evidente, acaso por la orientación intelectual de su director, y aunque Mar del Sur desea "navegar con eficacia entre las playas firmes de la tierra peruana y los anchos caminos de la cultura universal" (Mar del Sur, 1948 , p. 2), la mayoría de sus propuestas ensayísticas y comentarios críticos están abocados no a la literatura última y las manifestaciones recientes de las vanguardias y el arte universal, sino a la historia colonial y decimonónica, y a la literatura peruana del pasado ${ }^{23}$. Quizá por eso Bruno Podestá (1977) afirma que un rasgo de Mar del Sur son los “temas de exhibición erudita” (p. 72) La revista, es cierto, no es una publicación divulgativa. Su formato es más académico y está destinado a las élites intelectuales de la ciudad ${ }^{24}$.

Si queremos saber cuál es el aspecto de esta revista que dialoga más con otros proyectos modernizadores de los años cuarenta y cincuenta, debemos mencionar la poesía y las reseñas. Como ya habíamos afirmado en líneas anteriores, gran parte de los poetas nacidos entre 1920 y 1930 aproximadamente encontrarán en Mar del Sur, así como en Letras Peruanas (1951-1963), un espacio idóneo para su expresión literaria, en muchos casos inicial: desde Jorge E. Eielson y Blanca Varela hasta Leopoldo Chariarse y Pablo Guevara, entre otros. El segundo aspecto son las reseñas. La revista contiene una pequeña sección llamada "Crónica", en la que se comentan sucesos culturales de la ciudad, publicaciones importantes, conversatorios, presentaciones de teatro y conferencias. Este registro intelectual de la cultura en Lima se complementa con la enorme cantidad de reseñas que presenta Mar del Sur sobre libros y revistas coetáneos. Algunos de los reseñistas frecuentes son Luis Jaime Cisneros, José María Arguedas, Aurelio Miró Quesada Sosa, Alberto Tauro, Jorge Puccinelli, Daniel Valcárcel, Francisco Bendezu, S. Salazar Bondy, Francisco Miró Quesada, Luis Monguió, Emilio Harth-Terré, José Agustín de la Puente, Guillermo Lohmann y Paul Linder, además de otros jóvenes como Washington Delgado, Abelardo Oquendo, Luis Loayza, Leopoldo Chiappo, Luis Alberto Ratto y Alberto Varillas. La mayoría de reseñas pertenecen, por supuesto, a Luis Jaime Cisneros, espíritu infatigable que coordinaba gran parte de las publicaciones de la revista ${ }^{25}$. Como un buen faro intelectual del momento, durante casi seis años, Mar del Sur presta atención, en sus reseñas, a otras revistas de Lima: Mercurio Peruano, Letras, San Marcos, Las Moradas, Fénix, Documenta. Revista de la Sociedad Peruana de Historia, Revista Histórica, al mismo tiempo que comenta a Tradición, importante revista cuzqueña, y a Gleba, revista literaria editada por jóvenes estudiantes de la Universidad Católica, entre quienes estaba Abelardo Oquendo. Por ejemplo, el diálogo de Mar del Sur con Las Moradas es evidente gracias a la labor de Luis Jaime Cisneros: todos los números de la revista de Westphalen son reseñados y comentados, estableciendo un debate que, lejos de 
aislar los contenidos de las revistas culturales (en un círculo elitista y cerrado), amplía la red de difusión de estos proyectores intelectuales. Así, por ejemplo, cuando el trayecto vital de Las Moradas se termina, Cisneros remata con una reflexión que engloba crítica, pero también decepción respecto a la indiferencia que el medio social presta a productores culturales tan valiosos como este:

\begin{abstract}
Varias veces hemos dicho, desde estas mismas columnas, lo que Las Moradas representa en el mundo de las letras peruanas. Hoy debemos poner, junto a nuestra repetida convicción, una pregunta. Corre por ahí la versión (privativo de los limeños es llenarnos de rumores) de que la revista de Westphalen ha cumplido su cometido. Nadie como nosotros sabe de los sinsabores que acarrea mantener una publicación de jerarquía; nadie ignora, sobre todo, lo que significa conservar la jerarquía y el equilibrio en el Perú, donde tan dados estamos a todas las aventuras y a todos los devaneos del orden, incluso los políticos. ¿Es este el último número de Las Moradas? ¿En esto puede acabar un programa mantenido a fuerza de dignidad y celo? ¿A esto estarán condenadas cuantas tentativas por evadirnos de la chatura mental que nos oprime haya de emprenderse en el Perú? (Cisneros, 1949, p. 93)
\end{abstract}

Cisneros, lector atento de las revistas de la época, se lamenta por esta importante pérdida, que no hace sino profundizar el perenne estado de "chatura mental" de la sociedad limeña. Es importante anotar que todas estas revistas, que son comentadas por Mar del Sur, forman parte de un clima cultural muy singular en la historia del país. Como ya habíamos dicho, muchos proyectos intelectuales fenecerán tras el restablecimiento del autoritarismo y la eliminación de las libertades. En julio de 1949, el gobierno del general Manuel Odría promulgó la "Ley de Seguridad Interior de la República", considerada una de las más draconianas y represivas de la historia peruana republicana. Esta ley establecía que "cometían delito contra la seguridad y tranquilidad pública los que, con fines políticos o sociales, atemoricen verbalmente, por escrito o cualquier otro medio a las personas, amenazándolas en su vida, su libertad o sus intereses materiales o morales... o de sus familiares" o los que "propugnen verbalmente, por escrito o por cualquier otro medio... noticias o informaciones falsas o tendenciosas, destinadas a alterar el orden público o a dañar el prestigio y crédito del país" (Norabuena Huamán, 1982, p. 145). Así, la libertad de opinión estaba vetada. Sin embargo, a partir de las evidencias, parece ser que esta situación generó, como efecto trampolín, la búsqueda de nuevas ventanas de expresión aparentemente "apolíticas", como la creación y la reflexión cultural, sobre todo en revistas (Aubès, 1992, p. 249). Por esa razón, podríamos afirmar que este fue uno de los factores que explica por qué, desde fines de los años cuarenta hasta bien entrada la década del cincuenta, veremos que Lima aumentará exponencialmente la cantidad de su producción cultural ${ }^{26}$. Según el investigador francés Gérald Hirschhorn (2005), lo que crecerá con evidencia será el número 
de elencos teatrales, galerías de exposición, conjuntos musicales, funciones de teatro, conciertos, exposiciones de arte, conferencias, y principalmente revistas culturales y literarias (pp. 31-46). Hirschhorn (2005) destaca 57 revistas culturales como las más importantes del medio limeño solo entre 1950 y 1965 (pp. 94-98).

\section{Conclusiones}

Durante el mandato de José Luis Bustamante y Rivero, el ambiente político de democracia que se empezaba a vivir después de muchos años, aunado al ánimo universal democrático luego de la victoria de los Aliados en mayo de 1945, gestó aún más el espíritu de libertad y la aparición de escritores que, independientemente de sus apuestas culturales, ejercían una voz de cambio que estuviera direccionada por principios ético-democráticos y no por intereses partidarios o políticos.

De acuerdo con el contexto que vivía Lima en la segunda mitad de los años cuarenta, una plataforma modernizadora puede entenderse como el espacio físico, escrito, visual o simplemente discursivo que, apoyado por medios propios de la dinámica de la vida cultural y cívica de una ciudad busca modernizar el imaginario cultural de sus habitantes, ya sea defendiendo los ideales de libertad y democracia, promoviendo una apertura a valores culturales contemporáneos provenientes del extranjero, impulsando el reconocimiento de otras tradiciones culturales, o combatiendo las ideologías autoritarias de las clases dominantes, el indigenismo ortodoxo en la pintura, el hispanismo exacerbado o las corrientes que reivindicaban una literatura bajo el yugo político.

Las Moradas se caracterizó por dejar de lado condicionamientos locales o particulares como el indigenismo o el hispanismo anticuado; reivindicar toda obra por su renovadora expresión formal; sublimar la experiencia espiritual del individuo como componente fundamental en la creación, y rescatar la tradición precolombina en tanto saber primigenio del hombre. Esta revista prestará especial atención a las corrientes artísticas y literarias en boga en la Europa de Posguerra, como el surrealismo, el abstraccionismo en la pintura, la arquitectura moderna y el interés por las tradiciones culturales no occidentales.

La Agrupación Espacio engloba a un conjunto de artistas plásticos, escritores, arquitectos y estudiantes de la antigua Escuela Nacional de Ingenieros (hoy Universidad Nacional de Ingeniería), todos ellos liderados por el arquitecto y periodista Luis Miró Quesada Garland. El grupo tenía como objetivo impulsar una arquitectura y arte modernos en el país, buscando el encuentro del hombre nuevo, el hombre contemporáneo, con su espacio y momento universal.

El Correo de Ultramar recorre los caminos actuales de la literatura y el arte principalmente europeos (enfatizando el caso de Francia), además de prestar 
atención a autores nacionales como Eielson, Salazar Bondy y Vallejo. Una característica importante de la revista es que se propone ser un espacio de integración y producción de valores culturales en Lima.

La Peña Pancho Fierro fue una institución que batalló para lograr revalorar el arte popular. Fue fundada en 1937 por las hermanas Alicia y Celia Bustamante. La Peña constituyó un lugar fundamental desde el cual el saber de la cultura andina irradió a distintos artistas, intelectuales y escritores limeños e incluso extranjeros. El lugar funcionó como sala de exposiciones artísticas, punto de encuentro y sobre todo salón de discusión intelectual.

Mar del Sur es una revista que abarca casi todas las áreas vinculadas a la cultura: poesía, filosofía, estética, relatos, ensayos históricos, arte plástico, filología y hasta estudios técnicos sobre problemas específicos en diversas zonas del país. Sus intereses descansaron principalmente en la historia y la cultura de los periodos colonial y republicano en el Perú, las crónicas de la conquista, las reflexiones sobre poesía y los ensayos dedicados a la filosofía y la cultura clásica europea.

\section{Notas}

1 Es importante anotar que, luego del abrupto final del gobierno de Augusto Bernardino Leguía (1919-1930), el país ingresa en un periodo de alta conflictividad social: el tercer militarismo (Jorge Basadre) no solo supone una etapa de la vida del país en que el poder oligárquico se enfrenta directamente con las agrupaciones políticas (el APRA y el Partido Comunista, principalmente) que buscaban las reivindicaciones sociales tanto tiempo negadas, sino que las libertades cívicas y de expresión se verán seriamente perjudicadas, además de que el propio interés por las instituciones y plataformas de producción cultural decaerá considerablemente. Nos encontramos también en un periodo en que las ideologías autoritarias, acicateadas por la influencia de los totalitarismos europeos, ha sabido campear en algunos sectores de las clases dominantes del país. Sin embargo, este espectro cultural, a todas luces desalentador, comenzará a cambiar hacia fines de la década de 1930: no solo el país será sede de la VIII Conferencia Interamericana, sino que aparecerá la Orquesta Sinfónica Nacional e instituciones culturales como Ínsula, la Asociación de Artistas Aficionados, el Instituto Cultural Peruano Norteamericano y la Asociación Nacional de Escritores y Artistas. Del mismo modo, luego de los oscuros primeros años de esa década, empezarán a surgir revistas culturales que, de alguna manera, intentan combatir la forma unívoca de concebir la cultura que las elites del país intentan, a través de sus medios de comunicación (El Comercio, La Prensa o La Crónica), difundir en el imaginario peruano. Algunas de estas revistas son, por citar un ejemplo, Palabra. En defensa de la Cultura (1936-1944), El boletín CADRE (1936-1937), El Uso de la Palabra (1939), Tres (1939-1941) e Historia (1943-1945), sin olvidar que existían también otras publicaciones culturales (Sphynx, Mercurio Peruano, Cultura Peruana, Turismo, entre otras) de carácter más bien conservador, al menos en sus primeros años. Todo este panorama irá modificándose con mayor evidencia en el gobierno de Manuel Prado (1939-1945) hasta alcanzar su mayor despliegue en 1945: año de la victoria de los Aliados en la Segunda Guerra Mundial y del inicio del periodo democrático de José Luis Bustamante y Rivero (1945-1948). 
2 A partir del reconocimiento de algunas publicaciones y proyectos culturales en los que, en los años 40, participa Jorge Eduardo Eielson, Rebaza Soraluz aprovecha para agrupar varios de ellos bajo la denominación de "plataformas modernizadoras", concepto con el estamos también de acuerdo.

3 En esta investigación, Luis Rebaza Soraluz ha rastreado el camino que ha seguido la evolución de los principales actores que buscaron la modernización en el espacio cultural peruano durante la década de 1940. Todos ellos (Eielson, De Szyszlo, Arguedas, Westphalen, Varela, Harth-Terré) se empeñaron en el diseño de narrativas culturales distintas, logrando hacer comprender que la conformación de un artista moderno (escritor, intelectual o artista plástico) en el Perú podía llevarse a cabo asumiendo diferentes tradiciones culturales: locales o foráneas, milenarias o contemporáneas. Creemos, por tanto, que el texto de Rebaza es, por supuesto, una lectura imprescindible para comprender las dinámicas culturales de los años 1940-1950.

4 La revista Historia (1943-1945) fue fundada y dirigida por Jorge Basadre. Se trató de una publicación dedicada principalmente al discurrir de temas históricos, aunque podemos afirmar que también ejerció un rol particular en esos años: discutir la actualidad política y cultural del país sin olvidar los sucesos contemporáneos del exterior (los acontecimientos de la guerra europea, por ejemplo). El ensayo, género que Basadre dominaba en su afán de conjugar historia y reflexión social, es el protagonista de esta revista, la cual reserva las más de sus páginas a textos de interpretación histórica, comentarios sobre la realidad social y reflexiones sobre arte y literatura, así como también apuntes provenientes de otras áreas de las ciencias sociales y el conocimiento académico. Por otro lado, Nuestro Tiempo apareció en enero de 1944 y su consejo de redacción estuvo conformado por Juan Ríos, Xavier Abril y Fernando Hernández de Agüero, quien aparecía como director. Nuestro Tiempo. Revista para la defensa de la Cultura nació como una plataforma de discusión sobre el derrotero del arte plástico en el Perú. Aunque en sus páginas también se abordaron temas de economía, cultura y literatura, parece ser la tradición pictórica peruana (y su senda futura) la apuesta que esta revista tomó, sobre todo en cuanto se refiere a la defensa de una pintura independiente.

5 Estamos de acuerdo con Rebaza Soraluz cuando sugiere no confundir el "modernismo" (modernism) o "vanguardia histórica" con el "modernismo hispanoamericano", movimiento imperante en Hispanoamérica a fines del siglo XIX e inicios del siglo XX.

6 Poeta y ensayista, E. A. Westphalen tuvo a su cargo, además de Las Moradas, tres revistas más: El uso de la palabra (1939), cuyo único número publicó en colaboración con César Moro; La Revista Peruana de Cultura (1963-1968), que dirigió temporalmente (1964-1966) por un pedido de su amigo José María Arguedas; y la conocida revista Amaru (1967-1971), editada gracias al apoyo de la Universidad Nacional de Ingeniería.

7 Es importante precisar, según lo propuesto por Marshall Berman (2006), las diferencias entre los conceptos de modernidad, modernización y modernismo. La modernidad (principalmente, la tercera fase de la modernidad) comprende el conjunto de cambios tecnológicos, industriales y demográficos que han rediseñado (y acelerado) la dinámica de la vida humana en los últimos dos siglos. La modernización, en cambio, supone "los procesos sociales que dan origen a esta vorágine [moderna], manteniéndola en un estado de perpetuo devenir". Y el modernismo implica el conjunto de ideas, valores y visiones que el hombre se ha forjado como reacción a estos procesos de modernización. (p. 2) Es el modernismo el que el que nos interesa, por cuanto su ámbito corresponde a la esfera de las ideas, la reflexión, la creación y, por tanto, el arte y la literatura. 
8 Para profundizar en el contenido de Las Moradas, sugerimos la lectura de los trabajos de Luis Loayza (2010), Françoise Aubès (1992), Luis Jaime Cisneros (2002), William Keeth (2012), Yolanda Westphalen Rodríguez (2015) y Luis Rebaza Soraluz (2017).

9 El periodo más enérgico de la Agrupación Espacio puede situarse entre fines de la década del cuarenta (mayo de 1947) e inicios de la década del cincuenta. Con el paso de los años, la agrupación irá feneciendo y será desde sus filas que nacerá el futuro Movimiento Social Progresista.

10 José Ignacio López Soria (1997) menciona, entre ellos, a Santiago Agurto Calvo, Javier Cayo, Adolfo Córdova, Carlos Cueto Fernandini, Mayaya Gamio Palacio, Celsa Garrido Lecca, Emilio Herman S., Enrique Iturriaga, Luis Miró Quesada Garland, Eduardo Neira, Samuel Pérez Barreto, Sebastián Salazar Bondy, Fernando de Szyszlo, Blanca Varela, Luis Vera, Carlos Williams, Leopoldo Chariarse, Jorge Piqueras, Carlos Espinoza, Carlos Rodríguez, Javier Sologuren y Jorge E. Eielson. (párr.1-19)

11 En su ensayo "El no-estilo geométrico y el urbartista peruano contemporáneo: la Agrupación Espacio", Rebaza Soraluz destaca casos como los de Emilio Herman Stava y H.A. (posiblemente Alberto H. Aranzaens), miembros de Espacio que, en el diario El Comercio, publican comentarios sobre teatro y poesía que dialogan directamente con las propuestas estéticas de Javier Sologuren, Sebastián Salazar Bondy y Jorge Eduardo Eielson.

12 Demostrando una estrecha adhesión ideológica, esta declaración de principios fue reproducida un mes después, en junio de 1947, por la revista El Arquitecto Peruano, cuyos miembros también eran, muchos de ellos, parte de la Agrupación Espacio. El Arquitecto Peruano (1937-1977) fue fundada por Fernando Belaúnde Terry y constituyó la publicación más importante sobre arquitectura peruana en el siglo XX. La revista estuvo ligada a miembros de la Sociedad de Arquitectos del Perú, así como a varios profesores del futuro Departamento de Arquitectura (creado en 1943) de la Escuela Nacional de Ingeniería: Fernando Belaúnde, Ricardo Malachowski, Héctor Velarde, Emilio Harth-Térre, Paul Linder, entre otros (Zapata, 1995, pp. 40-41). Antonio Zapata (1995) ha destacado a El Arquitecto Peruano como un proyecto con un "profundo contenido social", pues se interesó sobremanera por el proceso de urbanización de las zonas rurales, así como fue un decisivo puente intelectual entre las ideas de arquitectos extranjeros y el Perú, a la vez que contribuyó con la discusión teórica y la profesionalización de la carrera arquitectónica en el país (pp. 20-21).

13 Luis Rebaza Soraluz (2017) sostiene que Espacio dialoga con el proyecto de El Arquitecto Peruano, por cuanto recoge aspectos medulares de esta revista: modernización del Perú desde los centros urbanos hacia fuera; concepción biológica de la sociedad que permita un ordenamiento geométrico en unidades celulares; aplicación de la urbanística moderna según los modelos de Le Corbusier y Frank Lloyd Wright; continuación de la idea del urbanista como transformador de los órdenes sociales. (p. 149)

14 Es importante recordar que el director de Las Moradas, E. A. Westphalen, conocía bien la obra Jules Supervielle (1884-1960), con quien también intercambió correspondencia.

15 La revista tiene una sección llamada “Gaceta de París”, donde se reseñan algunos sucesos y eventos culturales de la capital francesa.

16 Esto nos hace pensar por qué Fernando de Szyszlo, en sus memorias, recuerda esta revista como una suerte de publicación generacional.

17 Podemos observar un ejemplo sobre cómo se continúa reivindicando una poética pictórica libre y moderna. Comentando las exposiciones de pintura montadas en esos meses, El Correo de Ultramar destaca los trabajos de Ricardo Grau, Juan Manuel de la Colina, Carlos Quispez Asín, Sérvulo Gutierrez y Judith Westphalen, al mismo tiempo que afirma que 
de todos los pintores invitados en una exposición colectiva "algunos continúan el cultivo lento y disciplinado del cubismo, otros se inclinan al fresco a la manera decididamente contemporánea, o permanecen con variedad de procedimientos, dentro de los lindes austeros del retrato o de la pintura valorista. La minoría de ellos se aferra todavía a un indigenismo anacrónico o a ese desventurado pintoresquismo publicitario que fuera el plato fuerte de nuestra pintura, hace algunos años." (E1 Correo de Ultramar, 1947d, p. 1)

18 "En los años cuarenta no había ninguna galería de arte en Lima. Si algún pintor importante iba a exponer, lo hacía en asociaciones culturales, en el Instituto Bach, en el AeroClub, o en tiendas de enmarcadores como la del señor Marini, al costado de la casa Welsch." (De Szyszlo, 2016, p. 76)

19 Sobre La poesía contemporánea del Perú (1946), sugerimos la revisión del exhaustivo estudio de Inmaculada Lergo Martín, en el que también se menciona que este libro entra en claro debate con la antología Radiografía de la literatura peruana con una antología de la vanguardia poética peruana, editada solo un año después (1947) por Arias-Larreta y en la que se reivindica una poesía subordinada a la lucha de clases y a las determinantes localistas y sociales.

20 Para entender las dimensiones culturales de la Peña Pancho Fierro, sugerimos la lectura del trabajo "Alicia y Celia Bustamante, la Peña Pancho Fierro y el Arte Popular" de Kelly Carpio y María Eugenia Yllia.

21 A partir de lo que anotan De Szyszlo (2016), Ina Salazar (2011) y Carpio e Yllia (2006), presentamos algunos nombres de los intelectuales que interactuaron en la Peña Pancho Fierro: Celia y Alicia Bustamante, Elvira Luza, José María Arguedas, Emilio Adolfo Westphalen, Judith Ortiz Reyes (Judith Westphalen), César Moro, José Sabogal, Julia Codesido, Enrique Camino Brent, Camilo Blas, Jorge E. Eielson, Sebastián Salazar Bondy, Javier Sologuren, Blanca Varela, Fernando de Szyszlo, Leonor Vinatea Cantuarias, Ricardo y Renée Tenaud, Federido Schwab, Chepa Valencia, Julio Gastiaburú, Juan Francisco Valega, Emilio Choy, Christopher Isherwood, Dámaso Alonso, León Felipe, Pedro Salinas, JeanLouis Barrault, Jean Villar, Margarita Xirgu, María Casares, Rafael Alberti, Pablo Neruda, Louis Jouvet, Madeleine Orezay, Corpus Barga, Arturo Jiménez Borja, Rosalía Avalos, Hugo Pesce, Manuel Checa, Enrique Iturriaga, Francisco Pinilla, Enrique y Manuel Solari Swayne, Irma Lostaunau, André Coyné, Carlos Williams, Carlos Cueto Fernandini, Lilly Caballero de Cueto, Francois Borricaud, Doris Gibson, Carmen y Anita Pizarro, Luis Miró Quesada Garland, Francisco Moncloa, Teresa Carvallo, Gertrud Solardi, Rubin De la Borbolla, John Murra, Joaquín Roca Rey, Walter Peñaloza, Sérvulo Gutierrez, y Emilio y Ana Macagno.

22 A partir del número 19, la revista replanteará sus objetivos y buscará un acercamiento a las problemáticas concretas del país. Iniciará así un conjunto de ensayos que tratarán temas agropecuarios, económicos y demográficos. No obstante, en la práctica, el estudio humanístico continuará siendo su principal objetivo.

23 Hay muchas excepciones, por supuesto, pero estas no ganan en número a la tendencia mayoritaria de la revista. Una de las excepciones mencionadas es una interesante nota que E.A. Westphalen publica sobre el nobel otorgado a T.S Eliot en 1948.

24 El apoyo publicitario de Mar del Sur, en su mayoría conformado por grandes empresas de la época, confirma esta afirmación.

25 Resulta interesante y valioso el papel renovador de Luis Jaime Cisneros como miembro responsable del comité editorial de dos revistas de la época como Mar del Sur y Mercurio Peruano. Su participación en ambas publicaciones merecería un estudio aparte. 
26 Para comprender mejor este periodo y sus dimensiones culturales, recomendamos los siguientes trabajos: "Autour de la génération des années cinquante au Pérou" (1989) de Françoise Aubès y Sebastián Salazar Bondy: pasión por la cultura (2005) de Gérald Hirschhorn.

\section{Referencias bibliográficas}

\subsection{Revistas, semanarios y diarios consultados (fuentes primarias)}

Amaru (Lima), 1967-1971.

Amauta (Lima), 1926-1930.

Boletín del Comité de Amigos de la República Española (Lima), 1936-1937.

Cultura Peruana (Lima), 1941-1965.

El Comercio (Lima), 1947.

El Arquitecto Peruano (Lima), 1937-1977.

El Correo de Ultramar (Lima), 1947.

El Uso de la palabra (Lima), 1939.

Historia. Revista Peruana de Cultura (Lima), 1943-1945.

La Nación (Lima), 1946-1947.

La Prensa (Lima), 1945, 1946

Las Moradas (Lima), 1947-1949.

Mar del Sur (Lima), 1948-1953.

Mercurio Peruano (Lima), 1919-2017.

Nuestro Tiempo (Lima), 1944.

Palabra. En defensa de la Cultura (Lima), 1936-1944.

Sphynx (Lima)

Tres (Lima), 1939-1941.

Turismo (Lima), 1936.

\subsection{Referencias bibliográficas citadas}

Agrupación Espacio. (1947). Expresión de principios de la "Agrupación Espacio". El Comercio.

Aubès, F. (1989). Autour de la génération des années cinquante au Pérou. En Les Médiations Culturelles (domaine ibérique et latino-américain) (103-112). Paris: Service des Publications Université de la Sorbonne Nouvelle Paris III.

Aubès, F. (1992). Las Moradas ou la frontière magique: la revue du poète péruvien Emilio Adolfo Westphalen (1947-1949). América: Cabiers du CRICCAL, 9-10, 247-258. 
Basadre, J. (1981). La vida y la historia. Lima: Industrial Gráfica S.A.

Carpio, K. y Yllia, M. (2006). Alicia y Celia Bustamante, la Peña Pancho Fierro y el Arte Popular. Illapa, 3, 45-60.

Cisneros, L. (1949, septiembre-octubre). Revistas. Mar del Sur, 7, 93-92.

Cisneros, L. (2002). Acercamiento a Las Moradas. Las Moradas, edición facsimilar, 1, IX-XXVI.

Contreras, C. y Cueto, M. (2013). Historia del Perú contemporáneo. Desde las luchas por la Independencia hasta el presente. Lima: IEP, PUCP, Universidad del Pacífico.

Cotler, J. (1987). Clases, Estado y Nación en el Perú. Lima: Instituto de Estudios Peruanos.

De la Cadena, M. (2004). Indígenas mestizos. Raza y cultura en el Cusco. Lima: Instituto de Estudios Peruanos.

De Szyszlo, F. (2012). Miradas furtivas. Antología de textos 1955-2012. Lima: Fondo de Cultura Económica.

De Szyszlo, F. (2016). La vida sin dueño. Memorias. Lima: Alfaguara.

Delgado, W. (2008). Para vivir mañana. Ensayos y conferencias de literatura. Lima: Fondo Editorial de la Universidad de Lima.

El Correo de Ultramar. (1947a). El Correo de Ultramar. El Correo de Ultramar, 1, 1.

El Correo de Ultramar. (1947b). La "Galería de Lima". El Correo de Ultramar, 4, 3.

El Correo de Ultramar. (1947c). Próxima inauguración de la "Galería de Lima". El Correo de Ultramar, $3,3$.

El Correo de Ultramar. (1947d). Tres exposiciones. Pintura contemporánea. El Correo de Ultramar, 2, 1 .

Gargurevich, J. (1991). Historia de la prensa peruana (1594-1990). Lima: La Voz Editores.

Hirschhorn, G. (2005). Sebastián Salazar Bondy. Pasión por la cultura. Lima: Instituto Francés de Estudios Andinos / Fondo Editorial de la UNMSM.

Keeth, W. (2012). El rol de la traducción en "Las Moradas". Revista de Crítica Literaria Latinoamericana, 75, 301-316.

Las Moradas. (1947a). Las Moradas. Las Moradas, 1, 107.

Loayza, L. (2010). Ensayos. Lima: Universidad Ricardo Palma. Editorial Universitaria.

López Soria,J. (1981). Notas para el estudio del fascismo peruano. En Elpensamiento fascista (1930-1945) (9-37). Lima: Mosca Azul Editores.

López Soria, J. (1997). Aproximaciones a la "Agrupación Espacio". Medio de Construcción. Revista mensual de diseño y construcción, 126, 18-23.

Mar del Sur. (1948, septiembre-octubre). Propósitos. Mar del Sur, 1, 1. 
Norabuena Huamán, T. (1982). La libertad de prensa en el Perú. Estudio crítico-bistórico desde la Independencia hasta 1974. Lima: Servicios de Artes Gráficas Diamagraf.

Podestá, B. (1977). Revistas peruanas de este siglo. Apuntes. Revista semestral de ciencias sociales, 6, 69-74.

Rebaza Soraluz, L. (2017). De ultramodernidades y sus contemporáneos. Lima: Fondo de Cultura Económica.

Rochabrún, G. (2009). Batallas por la teoría. En torno a Marx y el Perú. Lima: Instituto de Estudios Peruanos.

Salazar, I. (2011). José María Arguedas y Emilio Adolfo Westphalen: una amistad fundacional. En El río y el mar. Correspondencia José María Arguedas / Emilio Adolfo Westphalen (1939-1969) (7-35). Lima: Fondo de Cultura Económica.

Stastny, F. (1981). Las artes populares del Perú. Lima: Edubanco.

Zapata, A. (1995). El joven Belaúnde. Historia de la Revista El Arquitecto Peruano, 1937-1963. Lima: Librería Editorial Minerva.

Westphalen Rodríguez, Y. El fetiche de la carta y los polémicos tiempos modernos. El epistolario de César Moro a Emilio Adolfo Westphalen (1939-1955). Toulouse, Tesis para optar el Grado Académico de Doctora en Estudios Iberoamericanos. Université Toulouse 2 - Jean Jaurès 